\title{
Cost-utility analysis comparing laparoscopic vs open aortobifemoral bypass surgery
}

\author{
This article was published in the following Dove Press journal: \\ Vascular Health and Risk Management \\ 19 June 2017 \\ Number of times this article has been viewed
}

\section{Anne Helene Krog ${ }^{1,2}$ \\ Mehdi Sahba ${ }^{3}$ \\ Erik M Pettersen ${ }^{4}$ \\ Torbjørn Wisløff ${ }^{5,6}$ \\ Jon O Sundhagen ${ }^{2}$ \\ Syed SH Kazmi}

'Institute of Clinical Medicine, Faculty of Medicine, University of Oslo, ${ }^{2}$ Department of Vascular Surgery, Division of Cardiovascular and Pulmonary Diseases, Oslo University Hospital, Oslo, ${ }^{3}$ Department of Vascular Surgery, Østfold Central Hospital, Kalnes, ${ }^{4}$ Department of Vascular Surgery, Sørlandet Hospital HF, Kristiansand, ${ }^{5}$ Department of Health Management and Health Economics, University of Oslo, ${ }^{6}$ Norwegian Institute of Public Health, Oslo, Norway
Correspondence: Anne Helene Krog Institute of Clinical Medicine, University of Oslo, P.O box II7I, Blindern, 03 I8 Oslo, Norway

Email a.h.krog@medisin.uio.no
Objectives: Laparoscopic aortobifemoral bypass has become an established treatment option for symptomatic aortoiliac obstructive disease at dedicated centers. Minimally invasive surgical techniques like laparoscopic surgery have often been shown to reduce expenses and increase patients' health-related quality of life. The main objective of our study was to measure qualityadjusted life years (QALYs) and costs after totally laparoscopic and open aortobifemoral bypass Patients and methods: This was a within trial analysis in a larger ongoing randomized controlled prospective multicenter trial, Norwegian Laparoscopic Aortic Surgery Trial. Fifty consecutive patients suffering from symptomatic aortoiliac occlusive disease suitable for aortobifemoral bypass surgery were randomized to either totally laparoscopic $(n=25)$ or open surgical procedure $(n=25)$. One patient dropped out of the study before surgery. We measured health-related quality of life using the EuroQol (EQ-5D-5L) questionnaire at 4 different time points, before surgery and for 6 months during follow-up. We calculated the QALYs gained by using the area under the curve for both groups. Costs were calculated based on prices for surgical equipment, vascular prosthesis and hospital stay.

Results: We found a significantly higher increase in QALYs after laparoscopic vs open aortobifemoral bypass surgery, with a difference of 0.07 QALYs, $(p=0.001)$ in favor of laparoscopic aortobifemoral bypass. The total cost of surgery, equipment and hospital stay after laparoscopic surgery $(9,953 €)$ was less than open surgery $(17,260 €),(p=0.001)$.

Conclusion: Laparoscopic aortobifemoral bypass seems to be cost-effective compared with open surgery, due to an increase in QALYs and lower procedure-related costs.

Keywords: laparoscopy, aortobifemoral bypass, cost-utility, quality-adjusted life years, QALYs, EQ-5D, health-related quality of life, HRQoL, cost-effectiveness

\section{Introduction}

In patients with peripheral arterial disease (PAD), a significantly impaired healthrelated quality of life (HRQoL), due to reduction in walking ability and limb pain, has been reported. ${ }^{1-5}$ In patients with aortoiliac occlusive disease (AIOD), which is a manifestation of PAD, blood flow to the lower extremities can be improved with the help of either a totally laparoscopic or an open aortobifemoral bypass. The laparoscopic aortobifemoral bypass (LABF) has become an established treatment option for symptomatic AIOD at many dedicated centers. ${ }^{6-11}$ At Oslo University Hospital, we introduced the laparoscopic technique in $2005,{ }^{12-14}$ and since February 2013, we have been conducting a randomized controlled trial, ${ }^{15,16}$ to compare the early morbidity after the two treatment methods. 
Previous experiences with minimally invasive surgical techniques have been shown to improve HRQoL and reduce procedure-related expenses. ${ }^{17-21}$ The investigation concerning the relative effectiveness and safety of a new procedure compared with a standard procedure is of importance. Especially, for the health-service providers, the cost-effectiveness of any treatment is important in decision making. ${ }^{22}$ Similar to many other national health providers, the Norwegian government is increasingly focused on the cost-effectiveness of our health services, resulting in new national guidelines that describe that any new method has to be assessed for cost-effectiveness. ${ }^{23,24}$ Since we are conducting a study on a new treatment method, laparoscopic aortic surgery, it was relevant to perform a health economic evaluation. ${ }^{25}$ Rouers et al, performed a calculation of mean cost in LABF vs open aortobifemoral bypass surgery (OABF), and found decreased costs per patient in the laparoscopic group. ${ }^{26}$ However, the study was not randomized and they excluded the patients who were converted from laparoscopic to open surgery. No other known economical evaluations of LABF have been performed to this date.

The main objective of our study was to perform a cost-utility analysis by calculating QALYs and costs after totally laparoscopic vs open aortobifemoral bypass procedure.

\section{Patients and methods Design}

Since February 2013, we have been conducting a multicenter randomized controlled trial, Norwegian Laparoscopic Aortic Surgery Trial (NLAST), at the Department of Vascular Surgery, Oslo University Hospital. This project is a substudy of the NLAST, ${ }^{15,16}$ where patients with AIOD classified according to the Trans-Atlantic Inter-Society Consensus II (TASC-II) as type D lesions are randomized to either LABF or $\mathrm{OABF}^{27}$ Inclusion and exclusion were based on the following criteria.

\section{Inclusion criteria}

- Patient with AIOD, TASC-II type D lesions, ${ }^{27}$ and with symptoms in the form of:

o intermittent claudication, with patient-reported, painfree walking distance $<200 \mathrm{~m}$, and/or

o chronic critical lower limb ischemia with rest pain, ischemic ulcers or gangrene, duration of symptoms $>2$ weeks.

\section{Exclusion criteria}

- Eligible for endovascular procedure

- Chronic obstructive pulmonary disease (COPD) $\geq$ stage IV, GOLD classification ${ }^{28}$

- Symptomatic coronary heart disease

- Chronic heart failure, ejection fraction $<40 \%$

- Active cancer disease

- Hostile abdomen

- Abdominal aortic aneurysm $\geq 3.0 \mathrm{~cm}^{27}$

- Acute critical limb ischemia, duration of symptoms $\leq 2$ weeks

\section{Participants}

Three vascular surgery departments in the south-eastern region of Norway participated in the study.

\section{Intervention}

The patients underwent aortobifemoral bypass through a totally laparoscopic transperitoneal, retrocolic, prerenal approach described by Coggia et $\mathrm{a}^{29}$ or a traditional open technique through a midline laparotomy.

\section{Outcomes and perspective}

The main objectives of our study were to measure QALYs and costs after totally laparoscopic vs open aortobifemoral bypass procedure in order to assess the cost-effectiveness. Based on our cohort study, we expected a gain in HRQoL during the first 6 months and similar results in the 2 groups thereafter. ${ }^{13,14}$ The patients answered the EuroQol EQ-5D-5L questionnaire at 4 different time points; before surgery (baseline), and at 1, 3 and 6 months postoperatively. ${ }^{30,31}$ The costs included in this study are the cost of surgical equipment, prosthesis and the costs related to the hospital stay. We registered exact resource use during surgery for the first 3 open and 3 laparoscopic patients. This included all disposable and non-disposable surgical equipment. We then calculated a mean price for the resources during surgery for each group based on those 6 patients. As the 2 procedures are relatively standardized, we considered it to be sufficient to extrapolate from these 6 patients. The cost of hospital stay was calculated based on national data for price per day in a somatic ward. ${ }^{32}$ Costs included were only those that incurred during the hospital stay. We chose a health care sector perspective for the analysis.

\section{Randomization and blinding}

The patients were randomized to either $\mathrm{LABF}$ or OABF. We used block randomization and closed opaque envelopes. The sequence was random and unknown to the researchers. 
Blinding of researchers, surgeons and/or participants was not considered possible.

\section{Analysis and statistics}

The EQ-5D-5L questionnaire validated in Norwegian language, was completed at all 4 time points and HRQoL was estimated based on a value set from the UK, due to the lack of any available Norwegian value set. ${ }^{33,34}$ Since these are repeated correlated measurements, we calculated QALYs using area under the curve (AUC) for both groups. Deceased patients were set to have a quality of life equal to 0 after death. One QALY was defined as 1 year of perfect health (reported by patients). Systemic morbidity was defined as all non-fatal complications related to the surgical procedure, excluding complications related to the graft and wound. ${ }^{35}$ No discounting of costs or health effects was performed due to the short time horizon of the analyses. Categorical variables were summarized as frequencies and continuous variables by the median and interquartile range. Comparisons between the two treatment groups were performed by using the MannWhitney $U$-test for continuous variables, and Fisher's exact test for categorical variables. A generalized linear model with gamma family and log link function was used to analyze differences in QALYs and costs. The results were controlled for confounding factors and baseline values, including baseline EQ-5D-5L score. There were missing values for 1 patient at 3 and 6 months, we imputed the mean value for the same treatment group at each time point. To give an impression of uncertainty in the overall estimates of cost-effectiveness, we performed 1000 bootstrap samples and presented incremental cost $(\Delta$ costs) and incremental effect ( $\triangle$ QALYs) between LABF and OABF. This cost-utility is a within trial analysis of a larger ongoing randomized trial, NLAST; therefore, an individual power analysis was not conducted for this substudy. Statistical significance was set at a 5\% level $(p<0.05)$. The software used for statistical analyses were Epi Info (Epi $\mathrm{Info}^{\mathrm{TM}}$ software, Centers for Disease Control and Prevention, Atlanta, GA, USA), IBM SPSS statistics version 22.0 (IBM corporation, Armonk, NY, USA) and Microsoft Office Excel ${ }^{\mathbb{B}}$ (Microsoft, Redmond campus, Redmond, WA, USA).

\section{Ethics}

The project was voluntary and participants gave an informed, written consent. The trial was approved by the Regional Committee for Medical and Health Research Ethics (REC, region south-east of Norway, registration number 2012/1367). The trial was registered at www.clinicaltrials.gov, with the registration number NCT01793662.

\section{Results}

\section{Participant flow and recruitment}

Fifty consecutive patients from the participating hospitals were included from February 2013 to February 2016. They were randomized to either LABF $(n=25)$ or $\operatorname{OABF}(n=25)$. The participant flow is described in Figure 1. The baseline characteristics of the patients in the two groups are given in Table 1. One laparoscopic procedure was converted from laparoscopic to open surgery due to bleeding. The patient was analyzed in the laparoscopic group, in accordance with the "intention-to-treat" principle. No patients were excluded after randomization. One patient dropped out after randomization and another did not wish to complete the follow-up program. One patient in the open group died of an acute myocardial infarction on the second postoperative day. This within trial analysis was completed after the inclusion of 50 patients.

\section{Outcomes and estimation}

Operative data and postoperative results are described in Table 2. Operation time was significantly longer in the

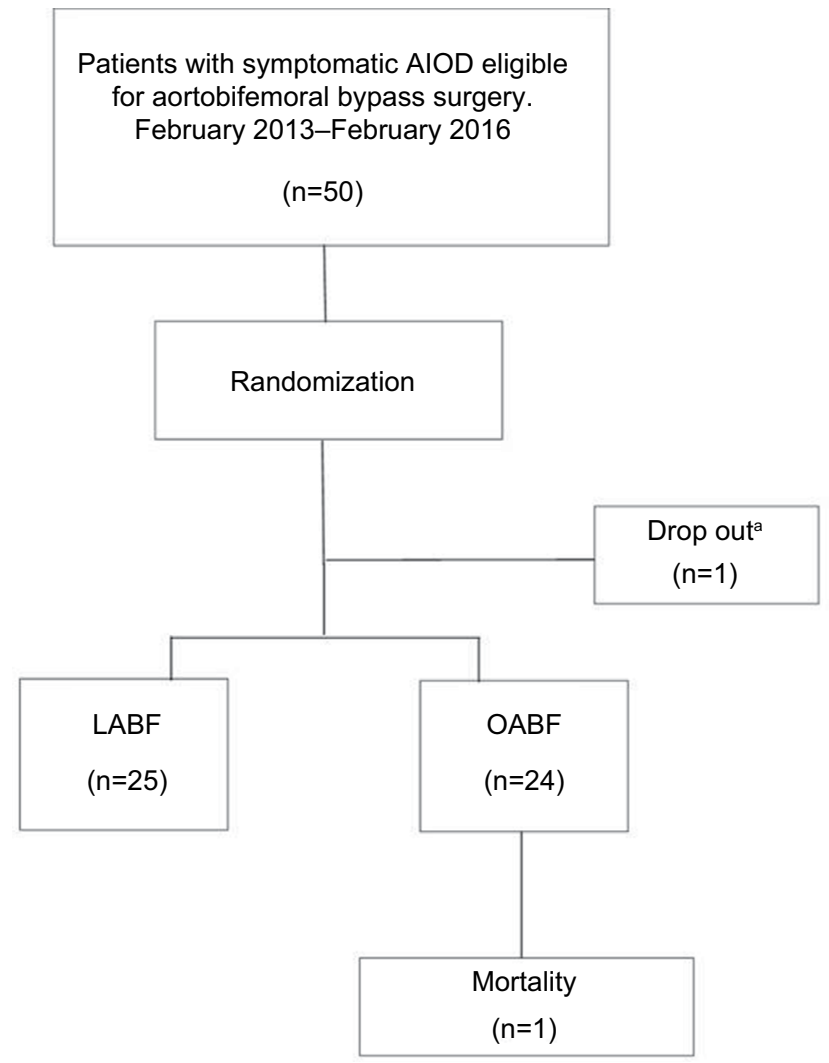

Figure I Flow chart of patient population with AIOD TASC-II type D lesion treated with either totally LABF or OABF.

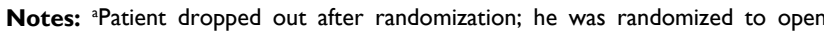
surgery.

Abbreviations: AIOD, aortoiliac occlusive disease; LABF, laparoscopic aortobifemoral bypass; OABF, open aortobifemoral bypass; TASC, Trans-Atlantic Inter-Society Consensus. 
Table I Baseline characteristics of patients treated with either totally laparoscopic or open aortobifemoral bypass for AIOD

\begin{tabular}{llll}
\hline Baseline characteristics & Laparoscopy, (N=25) & Open surgery, (N=24) & p-value \\
\hline Age in years, median (IQR) & $62.0(58.0-66.0)$ & $66.0(58.5-70.0)$ & $0.170^{\mathrm{a}}$ \\
Female gender N (\%) & $15(60.0)$ & $14(58.3)$ & $1.000^{\mathrm{b}}$ \\
Current smoker N (\%) & $12(48.0)$ & $15(62.5)$ & $0.393^{\mathrm{b}}$ \\
Hypertension (HT) N (\%) & $19(76.0)$ & $17(70.8)$ & $0.466^{\mathrm{b}}$ \\
COPD N (\%) & $4(16.0)$ & $6(25.0)$ & $0.335^{\mathrm{b}}$ \\
Diabetes mellitus (DM) N (\%) & $1(4.0)$ & $0(0)$ & $0.510^{\mathrm{b}}$ \\
Coronary heart disease (CHD) N (\%) & $2(8.0)$ & $7(29.2)$ & $0.060^{\mathrm{b}}$ \\
ASA classification, N (\%) & $0(0)$ & & $\mathrm{c}$ \\
ASA class 2. & $25(100.0)$ & $22(9.2)$ & $\mathrm{c}$ \\
ASA class 3. & $0(0)$ & $1(4.2)$ & $\mathrm{c}$ \\
ASA class 4. & $19(76.0)$ & $19(79.2)$ & $5(20.8)$ \\
Fontaine classification, N (\%) & $5(20.0)$ & $0(0)$ & $0.157^{\mathrm{a}}$ \\
Fontaine class 2b. & $\mathrm{I}(4.0)$ & $0.48(0.39-0.6 \mathrm{I})$ & \\
Fontaine class 3. & $0.58(0.46-0.73)$ & \\
Fontaine class 4. &
\end{tabular}

Notes: ${ }^{a}$ Mann-Whitney $U$-test, ${ }^{b}$ Fisher's exact test, 'statistical testing not appropriate. Fontaine classification: a classification of symptoms in peripheral atherosclerotic disease.

Abbreviations: IQR, interquartile range; AIOD, aortoiliac occlusive disease; COPD, chronic obstructive pulmonary disease; ASA, American Society of Anesthesiologists classification.

Table 2 Operative and postoperative characteristics of patients treated with either totally laparoscopic or open aortobifemoral bypass for AIOD

\begin{tabular}{llll}
\hline Outcome & Laparoscopy, N=25 & Open surgery, N=24 & P-value \\
\hline Operation time (minutes), median (IQR) & 22 I (203-248) & $196(160-230)$ & $0.024^{\mathrm{a}}$ \\
Postoperative stay in hospital(days), median (IQR) & $4.0(3.0-5.0)$ & $7.0(6.0-9.0)$ & $0.000^{\mathrm{a}}$ \\
Thirty-day hospital readmission, N (\%) & $2(8.0)$ & $4(16.7)$ & $0.314^{\mathrm{b}}$ \\
Thirty-day mortality, N (\%) & $0(0)$ & $1(4.2)$ & $0.490^{\mathrm{b}}$ \\
Thirty-day systemic morbidityc, N (\%) & $2(8.0)$ & $6(25.0)$ & $0.1 I^{\mathrm{b}}$ \\
Thirty-day total morbidity (systemic and local ${ }^{\mathrm{b}}$ ), N (\%) & $7(28.0)$ & $13(54.2)$ & $0.058^{\mathrm{b}}$ \\
\hline
\end{tabular}

Notes: ${ }^{a}$ Mann-Whitney U-test, bisher's exact test, 'systemic morbidity was defined as all non-fatal complications related to the surgical procedure, excluding complications related to the graft and wound, local morbidity was defined as complications related to the graft and wound.

Abbreviation: IQR; interquartile range; AIOD, aortoiliac occlusive disease.

LABF group, but they had shorter postoperative hospital stay than the open group, 4.0 vs 7.0 days, $p<0.001$. There was no statistically significant difference between the two groups in terms of morbidity and mortality; however, there seem to be a tendency toward less total morbidity after LABF, $p=0.058$.

HRQoL-scores based on EQ-5D-5L for the two groups, at baseline and during follow-up are presented in Figure 2. HRQoL is higher during follow-up in the laparoscopic group at all survey time points. Although, there is a small difference in HRQoL at baseline, this difference was not statistically significant. At the single time point measurements; only the difference at 1 month is statistically significant. AUC was calculated for these repeated correlated measurements of HRQoL in both groups. Total QALYs gained were calculated by AUC as HRQoL multiplied by follow-up time. The LABF group had a significantly higher gain in QALYs, with a difference of 0.07 QALYs, $p=0.001$. The costs of resources (hospital stay, surgical equipment and vascular prosthesis) are presented in Table $3 .^{32}$ The operative equipment was more expensive in the LABF group. However, the total cost per patient is much less in the LABF group compared with the OABF group, $9,953 €$ vs $17,260 €, p=0.001$ (Table 4). The higher gain in QALYs and lower costs are also demonstrated in a scatter plot showing costs and QALYs for each patient (Figure 3A). The open group has more extreme values, both with regard to costs and HRQoL. The uncertainty surrounding the mean estimates of incremental costs and QALYs, based on bootstrapping, are demonstrated in Figure 3B. The Figure $3 \mathrm{~B}$ shows a high probability that $\mathrm{LABF}$ is both more effective and less costly than OABF.

We used a generalized linear model to control for possible confounding effects. The difference in QALYs was still significantly in favor of laparoscopy after controlling 
for the confounding effects of coronary heart disease, COPD, hypertension, diabetes, EQ-5D-5L score before surgery, smoking and chronic critical ischemia $(p=0.008)$. The multivariate regression analysis also showed that the difference in total cost per patient were significantly in favor of laparoscopy, after controlling for the confounding effects of coronary heart disease, COPD, hypertension, EQ-5D-5L before surgery and chronic critical ischemia $(p<0.001)$.

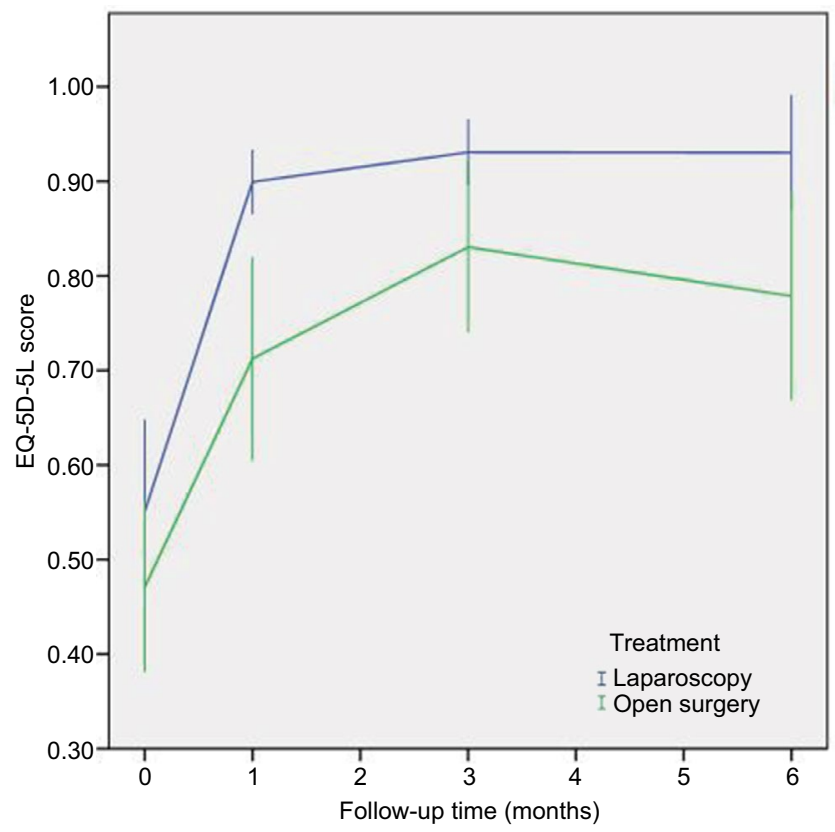

Error Bars: $95 \% \mathrm{Cl}$

Figure 2 Health related quality of life presented as mean EQ-5D-5L score at baseline and during follow-up after LABF vs OABF

Notes: Error bars represent the $95 \% \mathrm{Cl}$.

Abbreviations: LABF, laparoscopic aortobifemoral bypass; OABF, open aortobifemoral bypass; EQ-5D-5L, EuroQol questionnaire.

\section{Discussion}

\section{Summary}

We found significantly higher gain in QALYs and lower costs after laparoscopic vs open aortobifemoral bypass surgery. This gain maintained its statistical significance even after controlling the results for baseline differences in HRQoL and other confounding variables.

\section{Discussion}

EQ-5D is the most commonly used quality of life questionnaire in health economic evaluations, and it is easy and highly tolerated by patients. ${ }^{36,37}$ Another tool might detect smaller differences, but as long as the results are unambiguous in favor of laparoscopy, this would likely not influence our conclusions. ${ }^{36}$ We chose a generic quality of life questionnaire to capture the differences between the two groups. A disease specific tool could have been better to assess symptoms and deterioration in HRQoL due to PAD, but would not necessarily capture the differences comparing laparoscopy with laparotomy, which was our main objective. ${ }^{38}$ Additionally, neither of the disease-specific questionnaires are validated for the economic analysis ${ }^{25}$ nor made available in the Norwegian language. Although we used a UK tariff for valuing EQ-5D, we do not think the results would have been altered if a Norwegian value set had been available.

HRQoL is the primary indication of treatment and main benefit in revascularization surgery in patients with PAD. ${ }^{2,3}$ Some have argued the lack of "hard data", like morbidity and mortality, in these cost-utility evaluations and have also uttered concerns about the use of QALYs and its role in decision making. ${ }^{22,39,40}$ However, there are no known differences in

Table 3 Resources and estimation of cost per patient comparing totally LABF with OABF

\begin{tabular}{|c|c|c|c|}
\hline Resources & $\begin{array}{l}\text { Laparoscopy, } \\
\text { unit cost }(€)\end{array}$ & $\begin{array}{l}\text { Open surgery, } \\
\text { unit cost }(€)\end{array}$ & Source \\
\hline $\begin{array}{l}\text { I day of postoperative } \\
\text { hospital stay }\end{array}$ & 1,726 & $\mathrm{I}, 726$ & SAMDATA 2014, Norwegian Health Directorate (Huseby et $\mathrm{al}^{32}$ ) \\
\hline Surgical equipment & I,457 & 516 & $\begin{array}{l}\text { Estimated mean price of all surgical equipment (disposable and } \\
\text { non-disposable) from } 3 \text { LABF and } 3 \text { OABF. (price based on 20/4) }\end{array}$ \\
\hline Vascular prosthesis & 419 & 419 & Manufacturer (price based on 2014) \\
\hline
\end{tabular}

Abbreviations: LABF, laparoscopic aortobifemoral bypass; OABF, open aortobifemoral bypass.

Table 4 Comparing mean total costs in Euro $(€)$ and quality-adjusted life years (QALYs) after LABF vs OABF

\begin{tabular}{|c|c|c|c|c|c|c|}
\hline & \multirow[t]{2}{*}{ LABF } & \multirow[t]{2}{*}{ OABF } & \multicolumn{2}{|c|}{ Direct estimate } & \multicolumn{2}{|c|}{ Regression estimate } \\
\hline & & & Difference & $P$-value & Difference & $P$-value \\
\hline Mean total cost per patient $(€)$ & 9,953 & 17,260 & $-7,307$ & $0.00 I^{\mathrm{a}}$ & $-7,429$ & $<0.001$ \\
\hline QALYs & 0.45 & 0.38 & 0.067 & $0.00 I^{a}$ & 0.066 & 0.008 \\
\hline
\end{tabular}

Notes: aMann-Whitney U-test.

Abbreviations: LABF, laparoscopic aortobifemoral bypass; OABF, open aortobifemoral bypass; QALY, quality-adjusted life years. 


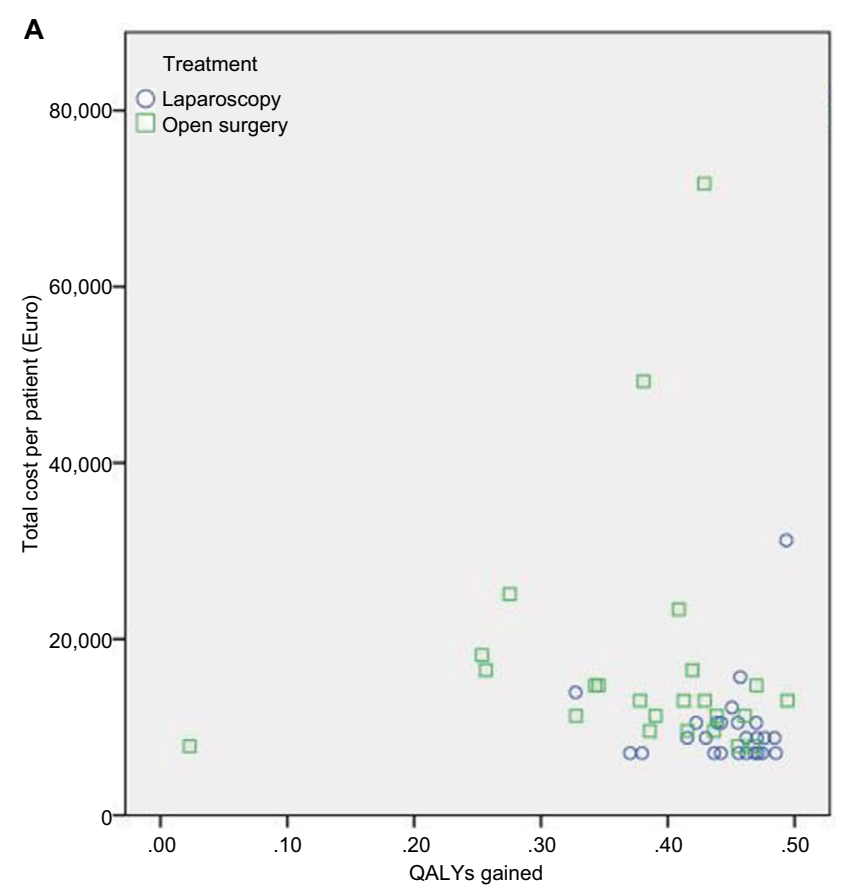

B

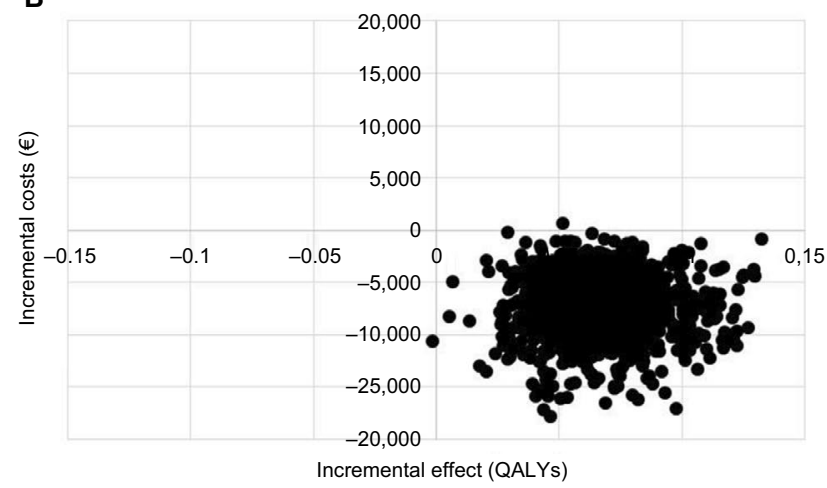

Figure 3 (A) Scatter plot. Costs per QALYs gained comparing totally LABF with OABF; (B) Incremental cost ( $\triangle$ costs) and incremental effect ( $\triangle Q A L Y s)$ between $\angle A B F$ and OABF based on bootstrapping.

Abbreviations: LABF, laparoscopic aortobifemoral bypass; OABF, open aortobifemoral bypass; QALYs, quality-adjusted life years; $€=$ Euro.

morbidity or mortality between LABF and OABF for AIOD to this day. ${ }^{9,11}$ Hence, a cost-utility is an appropriate tool for comparing two procedures, combining the patient-reported quality of life with an economic perspective.

The implementation of laparoscopic aortic surgery, has been slow. ${ }^{11}$ However, gradually there has been published evidence that the LABF combines the benefits of a minimally invasive technique with the excellent long-term patency rates of OABF for the treatment of AIOD. ${ }^{7,13}$ In the present study, we have demonstrated higher postoperative HRQoL combined with lower costs after LABF compared with OABF. This is an important finding and should be of interest to health providers, as well as for the patients suffering from AIOD in need of an aortobifemoral bypass.
The incremental cost-effectiveness ratio (ICER) can be defined as a price per effect (health) gained. The level of willingness to pay for a treatment can be used as a threshold. The ICER should be below this threshold, and thereby can be used as a tool in decision making. Norway is a country where hospital expenses are fully covered by the government. There are no strict requirements, for the time being, for the reporting of HRQoL in health technology assessment processes in Norway, but the focus is increasing. Although a threshold on the price of a QALY has not been set, a recent attempt of estimating the threshold empirically for Norway, resulted in a range of $€ 43,000$ to 94,000 per QALY gained..$^{41}$ Interventions resulting in increased health and decreased resource use, as is the case of LABF in our study, are in health economics regarded as "dominant". ${ }^{42}$ In easier terms; "one saves money and provide a better result". By definition, these dominant interventions are below the suggested or estimated thresholds, and should be considered as replacement for the comparative treatment. ${ }^{42}$ Based on these assumptions and the result of our study, one may suggest that the patients with symptomatic AIOD TASC II type D lesions should be offered a LABF instead of an OABF procedure.

We have followed the patients in this study for only 6 months. In other patient groups, it has been shown that the benefits of laparoscopic surgery are mostly gained during the first year, ${ }^{38,43,44}$ In our pilot study, the main effect on HRQoL was during the first 6 months. ${ }^{14}$ Even if the difference between the 2 groups would later during follow-up decrease, there is no indication that the benefits in terms of HRQoL and spared economic costs will be in favor of other than LABF. There also seem to be no negative long-term effects of LABF for AIOD. ${ }^{7}$ Given the assumption of laparoscopy being a dominant intervention at 6 months, which was also confirmed by our analyses, we found no reason to include longer term considerations in the analysis.

We have, in our study, found the main cause of costs is the hospital stay, which is significantly shorter after laparoscopic surgery, mean 4.0 vs 7.0 days. All doctors with the vascular departments were involved in the postoperative evaluation and care of the patients, and all patients were discharged when they met the following discharge-criteria; able to walk, oral intake of food, normal urination/defecation and no untreated ongoing local or systemic complication. We have no indication of any protocol-driven resources.

We used national data for cost per day in hospital. ${ }^{32}$ This number is calculated as a mean for all types of admissions in somatic specialist health care in Norway, and may not apply for our patients and wards. We know that laparoscopic 
equipment is expensive, there is more use of disposable equipment and also the operation time is longer. However, the total length of stay in hospital is significantly lower in the LABF group. This might outweigh any increased equipment costs and operation time costs. An opportunity cost evaluation ${ }^{45}$ and a micro cost analysis ${ }^{46}$ would be useful to assess the costs of the procedure and hospital stay even more specifically.

Generalizability and external validity are of importance when combining an economic evaluation with a clinical trial. We aimed to include all patients eligible for surgery and our inclusion/exclusion criteria reflect the clinical world. Multiple testing and repeated measurements on a small population can weaken the statistical analysis. This influences the strength of the conclusion. ${ }^{25}$ However, our results are strong and highly significant. We are the first to investigate these outcomes in a randomized setting, and this might affect decision makers. Further research is necessary to investigate the validity of the results and possible clinical implications.

\section{Conclusion}

LABF leads to an increase in QALYs gained and lower treatment costs, and seems to be cost-effective compared with open surgery.

\section{Acknowledgments}

We are thankful to all participating hospitals and staff for their help. Especially, we are very thankful to the late Professor Jørgen J. Jørgensen MD, PhD, for all his help and guidance.

\section{Author contributions}

Conception and design: AHK, SSHK, TW, JOS. Data collection: AHK, MS, EMP, SSHK. Analysis and interpretation: AHK, TW. Statistical analysis: TW, AHK. Writing the article: AHK, SSHK, TW. Critical revision of the article: AHK, SSHK, TW, EMP, MS, JOS. Final approval of the article: AHK, SSHK, TW, EMP, MS, JOS. Overall responsibility: AHK, SSHK. All authors contributed toward data analysis, drafting and revising the paper and agree to be accountable for all aspects of the work.

\section{Disclosure}

The authors report no conflicts of interest in this work.

\section{References}

1. Forbes JF, Adam DJ, Bell J, et al. Bypass versus Angioplasty in Severe Ischaemia of the Leg (BASIL) trial: health-related quality of life outcomes, resource utilization, and cost-effectiveness analysis. JVasc Surg. 2010;51(5 Suppl):43S-51S.
2. Currie IC, Wilson YG, Baird RN, Lamont PM. Treatment of intermittent claudication: the impact on quality of life. Eur J Vasc Endovasc Surg. 1995;10(3):356-361.

3. Pell JP. Impact of intermittent claudication on quality of life. The Scottish Vascular Audit Group. Eur J Vasc Endovasc Surg. 1995;9(4):469-472.

4. Spronk S, White JV, Bosch JL, Hunink MG. Impact of claudication and its treatment on quality of life. Semin Vasc Surg. 2007;20(1):3-9.

5. Moneta GL, Landry GJ, Nguyen LL. Does lower-extremity bypass improve quality of life? Is it cost effective? Semin Vasc Surg. 2009;22(4):275-280.

6. Coggia M, Javerliat I, Di Centa I, et al. Total laparoscopic bypass for aortoiliac occlusive lesions: 93-case experience. J Vasc Surg. 2004;40(5): 899-906.

7. Lecot F, Sabbe T, Houthoofd S, Daenens K, Fourneau I. Long-term results of totally laparoscopic aortobifemoral bypass. Eur JVasc Endovasc Surg. 2016;52(5):581-587.

8. Tiek J, Remy P, Sabbe T, et al. Laparoscopic versus open approach for aortobifemoral bypass for severe aorto-iliac occlusive disease-a multicentre randomised controlled trial. Eur J Vasc Endovasc Surg. 2012;43(6):711-715.

9. Bruls S, Quaniers J, Tromme P, Lavigne JP, Van Damme H, Defraigne JO. Comparison of laparoscopic and open aortobifemoral bypass in the treatment of aortoiliac disease. Results of a contemporary series (2003-2009). Acta Chir Belg. 2012;112(1):51-58.

10. Nio D, Diks J, Bemelman WA, Wisselink W, Legemate DA. Laparoscopic vascular surgery: a systematic review. Eur JVasc Endovasc Surg. 2007;33(3):263-271.

11. Helgetveit I, Krog AH. Totally laparoscopic aortobifemoral bypass surgery in the treatment of aortoiliac occlusive disease or abdominal aortic aneurysms - a systematic review and critical appraisal of literature. Vasc Health Risk Manag. 2017;13:187-199.

12. Kazmi SSH, Sundhagen JO, Florenes TL, Kroese AJ, Jorgensen JJ. Laparoscopic aortic surgery. [Norwegian] Laparoskopisk aortakirurgi. Tidsskr Nor Laegeforen. 2007;127(11):1518-1520.

13. Kazmi SS, Jørgensen JJ, Sundhagen JO, et al. A comparative cohort study of totally laparoscopic and open aortobifemoral bypass for the treatment of advanced atherosclerosis. Vasc Health Risk Manag. 2015;11:541-547.

14. Kazmi SSH, Krog AH, Berge ST, Sundhagen JO, Sahba M, Falk RS. Patient perceived health-related quality of life before and after laparoscopic aortobifemoral bypass. Vasc Health Risk Manag. 2017;13:169-176.

15. Krog AH, Sahba M, Pettersen EM, et al. Comparison of the acute-phase response after laparoscopic versus open aortobifemoral bypass surgery: a substudy of a randomized controlled trial. Vasc Health Risk Manag. 2016;12:371-378.

16. Krog AH, Thorsby PM, Sahba M, et al. Perioperative humoral stress response to laparoscopic versus open aortobifemoral bypass surgery. Scand J Clin Lab Invest. 2017;77(2):83-92.

17. Grant A, Wileman S, Ramsay C, et al. The effectiveness and costeffectiveness of minimal access surgery amongst people with gastrooesophageal reflux disease - a UK collaborative study. The REFLUX trial. Health Technol Assess. 2008;12(31):1-181, iii-iv.

18. Korolija D, Sauerland S, Wood-Dauphinée S, et al. Evaluation of quality of life after laparoscopic surgery: evidence-based guidelines of the European Association for Endoscopic Surgery. Surg Endosc. 2004;18(6):879-897.

19. Braga M, Frasson M, Zuliani W, Vignali A, Pecorelli N, Di Carlo V. Randomized clinical trial of laparoscopic versus open left colonic resection. Br J Surg. 2010;97(8):1180-1186.

20. Silistreli E, Catalyurek H, Karabay O, Hepaguslar H, Acikel U. Costeffectiveness of minimally invasive-intervention in aortofemoral revascularization. J Int Med Res. 2001;29(5):421-424.

21. Johnsen LG, Hellum C, Storheim K, et al. Cost-effectiveness of total disc replacement versus multidisciplinary rehabilitation in patients with chronic low back pain: a Norwegian multicenter RCT. Spine (Philadelphia, Pa 1976). 2014;39(1):23-32. 
22. Kind P, Lafata JE, Matuszewski K, Raisch D. The use of QALYs in clinical and patient decision-making: issues and prospects. Value Health. 2009;12 (Suppl 1):S27-S30.

23. Wisloff T. Priority-setting criteria in the Norwegian health services. Tidsskr Nor Laegeforen. 2015;135(15):1373-1375.

24. Norwegian-Directorate-of-Health-(Helsedirektoratet). The National System for the Introduction of New Health Technologies (methods) within the Specialist Health Service (Nasjonalt system for innføring av nye metoder i spesialisthelsetjenesten). Available from: https:// nyemetoder.no/english. Accessed October 1, 2015.

25. Ramsey SD, Willke RJ, Glick H, et al. Cost-effectiveness analysis alongside clinical trials II-An ISPOR Good Research Practices Task Force report. Value Health. 2015;18(2):161-172.

26. Rouers A, Meurisse N, Lavigne JP, et al. Potential benefits of laparoscopic aorto-bifemoral bypass surgery. Acta Chir Belg. 2005;105(6): 610-615.

27. Norgren L, Hiatt WR, Dormandy JA, Nehler MR, Harris KA, Fowkes FG. Inter-Society Consensus for the Management of Peripheral Arterial Disease (TASC II). J Vascul Surg. 2007;45 (Suppl S):S5-S67.

28. Gomez FP, Rodriguez-Roisin R. Global Initiative for chronic obstructive lung disease (GOLD) guidelines for chronic obstructive pulmonary disease. Curr Opin Pulm Med. 2002;8(2):81-86.

29. Coggia M, Bourriez A, Javerliat I, Goeau-Brissonniere O. Totally laparoscopic aortobifemoral bypass: a new and simplified approach. Eur J Vasc Endovasc Surg. 2002;24(3):274-275.

30. Herdman M, Gudex C, Lloyd A, et al. Development and preliminary testing of the new five-level version of EQ-5D (EQ-5D-5L). Qual Life Res. 2011;20(10):1727-1736.

31. EuroQol group. EuroQol-a new facility for the measurement of healthrelated quality of life. Health Policy. 1990;16(3):199-208.

32. Huseby BM, Kalseth B, Ødegaard H, et al. SAMDATA Spesialisthelsetjenesten 2014 (Data from the Norwegian Specialist Health Services); 2014. Available from: https://helsedirektoratet.no/Lists/Publikasjoner/ Attachments/989/SAMDATA\%202014\%20IS-2348.pdf. Accessed December 15, 2016.

33. Devlin N, Shah K, Feng Y, Mulhern B, Van Hout B. Valuing HealthRelated Quality of Life: An EQ-5D-5L Value Set for England; 2016. Available from: https://www.ohe.org/publications/valuing-health-relatedquality-life-eq-5d-51-value-set-england. Accessed January 16, 2017.
34. Nord E. EuroQol: health-related quality of life measurement. Valuations of health states by the general public in Norway. Health Policy. 1991;18(1):25-36.

35. Rutherford RB, Baker JD, Ernst C, et al. Recommended standards for reports dealing with lower extremity ischemia: revised version. J Vasc Surg. 1997;26(3):517-538.

36. Wisløff T, Hagen G, Hamidi V, Movik E, Klemp M, Olsen JA. Estimating QALY gains in applied studies: a review of cost-utility analyses published in 2010. Pharmacoeconomics. 2014;32(4):367-375.

37. Kaarlola A, Pettilä V, Kekki P. Performance of two measures of general health-related quality of life, the EQ-5D and the RAND-36 among critically ill patients. Intensive Care Med. 2004;30(12):2245-2252.

38. Korolija D, Sauerland S, Wood-Dauphinee S, et al. Evaluation of quality of life after laparoscopic surgery: evidence-based guidelines of the European Association for Endoscopic Surgery. Surg Endosc. 2004;18(6):879-897.

39. Follesdal A. [Should prioritization in health care programs be based on duty or care ethics or benefit ethics?]. Tidsskr Nor Laegeforen. 2003;123(20):2897-2898. Norwegian.

40. Schlander M. Measures of efficiency in healthcare: QALMs about QALYs? Z Evid Fortbild Qual Gesundheitswes. 2010;104(3):214-226.

41. Woods B, Revill P, Sculpher M, Claxton K. Country-level cost-effectiveness thresholds: initial estimates and the need for further rResearch. Value Health. 2016;19(8):929-935.

42. Drummond MF, Sculpher MJ, Claxton K, Stoddart GL, Torrance GW. Methods for the Economic Evaluation of Health Care Programmes. OUP Oxford; 2015.

43. Ng SS, Leung WW, Wong CY, et al. Quality of life after laparoscopic vs open sphincter-preserving resection for rectal cancer. World J Gastroenterol. 2013;19(29):4764-4773.

44. Janson M, Lindholm E, Anderberg B, Haglind E. Randomized trial of health-related quality of life after open and laparoscopic surgery for colon cancer. Surg Endosc. 2007;21(5):747-753.

45. Chatterjee A, Chen L, Goldenberg EA, Bae HT, Finlayson SR. Opportunity cost in the evaluation of surgical innovations: a case study of laparoscopic versus open colectomy. Surg Endosc. 2010;24(5):1075-1079.

46. Mishra V, Geiran O, Krohg-Sørensen K, Andresen S. Thoracic aortic aneurysm repair. Direct hospital cost and Diagnosis Related Group reimbursement. Scand Cardiovasc J. 2008;42(1):77-84.
Vascular Health and Risk Management

\section{Publish your work in this journal}

Vascular Health and Risk Management is an international, peerreviewed journal of therapeutics and risk management, focusing on concise rapid reporting of clinical studies on the processes involved in the maintenance of vascular health; the monitoring, prevention and treatment of vascular disease and its sequelae; and the involvement of
Dovepress

metabolic disorders, particularly diabetes. This journal is indexed on PubMed Central and MedLine. The manuscript management system is completely online and includes a very quick and fair peer-review system, which is all easy to use. Visit http://www.dovepress.com/ testimonials.php to read real quotes from published authors. 